\title{
JUDICIÁRIO E POLÍTICAS PÚBLICAS: UM EXEMPLO POSITIVO $^{1}$
}

THE JUDICIARY AND PUBLIC POLICIES: A POSITIVE EXAMPLE

PODER JUDICIAL Y POLÍTICAS PÚBLICAS: UN EJEMPLO POSITIVO

Danielle Anne Pamplona²

Eduardo Melo de Mesquita ${ }^{3}$

1 Os autores agradecem MUNIZ Advogados, na pessoa do Dr. Fernando Muniz, por gentilmente franquear aos autores as petições por si elaboradas e as decisões que deram fundamento ao presente artigo.

2 Professora Titular da Pós-Graduação e Graduação em Direito da Pontifícia Universidade Católica do Paraná; Doutora pela Universidade Federal de Santa Catarina. E-mail: danielle.pamplona@pucpr.br.

3 Mestre e Doutor pela Pontifícia Universidade Católica de São Paulo - PUC-SP e Pós-Doutorando pela Pontifícia Universidade Católica do Paraná - PUC-PR. E-mail: duna1@terra.com.br. 
Resumo: O presente ensaio tem como objetivo escandir o debate acerca da inserção do Poder Judiciário no âmbito das decisões políticas, a partir de uma situação concreta. A análise gira em torno do constitucionalismo contemporâneo e do modelo de democracia deliberativa, partindo-se de posições doutrinárias que defendem a intervenção judicial sempre que a decisão política afete direito individual. Enfrenta-se a questão portuária no Brasil como política pública, para apreciar a interferência do Poder Judiciário nessas políticas, com enfoques na doutrina alemã acerca do tema. A decisão que motivou a reflexão demonstra a nocividade da decisão política que frustra a participação popular em debate sobre política pública, pondo em cheque a norma constitucional que regula a participação dos interessados. Isso foi o que despertou o interesse de usar o caso para demonstrar a essencial inserção do Judiciário para restaurar a efetividade da norma constitucional.

Palavras-chave: Políticas públicas. Poder Judiciário. Democracia deliberativa. Constitucionalismo contemporâneo. Proporcionalidade.

Abstract: This essay analyzes the debate surrounding the inclusion of the judiciary in the context of political issues, based on a concrete situation. The analysis revolves around contemporary constitutionalism and the model of deliberative democracy, starting from doctrinal positions that defend judicial intervention whenever the political decision affects individual rights. The text faces the ports issue in Brazil as a public policy, to assess the interference of the judiciary on them, through the eyes of the German doctrine on the subject. The decision that prompted this reflection demonstrates the harmfulness of the political decision when it frustrates people's participation in important debates as demanded by constitutional law. That was what prompted our interest in using this case study to demonstrate the essential participation of the judiciary in restoring the effectiveness of the constitutional law.

Keywords: Public policies; Judiciary Power; Deliberative democracy; Contemporary constitutionalism; proportionality. 
Resumen: El presente ensayo tiene como objetivo escandir el debate acerca de la inserción del Poder Judicial en el ámbito de las decisiones políticas a partir de una situación concreta. El análisis gira alrededor del constitucionalismo contemporáneo y del modelo de democracia deliberativa, partiendo de posiciones doctrinarias que defienden la intervención judicial siempre que la decisión política afecte el derecho individual. En Brasil se enfrenta la cuestión portuaria como política pública, para apreciar la interferencia del Poder Judicial en esas políticas, con enfoques en la doctrina alemana acerca del tema. La decisión que motivó la reflexión demuestra la nocividad de la decisión política que frustra la participación popular en el debate sobre política pública, poniendo en jaque la norma constitucional que regula la participación de los interesados. Fue eso lo que despertó el interés por usar el caso para demostrar la esencial inserción del Poder Judicial para restaurar la efectividad de la norma constitucional.

Palabras clave: Políticas públicas. Poder Judicial. Democracia deliberativa. Constitucionalismo contemporáneo. Proporcionalidad.

\section{INTRODUÇÃO}

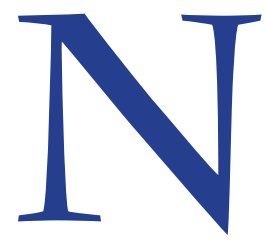
ão é de hoje que os debates acerca da possibilidade de intervenção judicial nas decisões políticas expressas por ou em políticas públicas são fervorosos. A justificativa para isso é que essa possibilidade reflete algo muito mais amplo, que é o conflito entre a opção pela regência do povo por uma Constituição e a opção pelo regime democrático.

Muito já foi dito acerca dos dois temas, tanto do constitucionalismo quanto da democracia. Parece ser acertada a posição de que o conflito que se configura é, em verdade, aparente, eis que um regime democrático carece de limitações diante da maioria e o constitucionalismo carece das inflexões que a maioria pode Ihe trazer 4 . Mas essa solução compromissória não é de fácil alcance no plano do ser, eis que definir e concretizar o funcionamento dos instrumentos que a

4 ROSSI, Amélia; PAMPLONA, Danielle Anne. Neoconstitucionalismo e ativismo judicial: democracia e constitucionalismo em oposição ou tensão produtiva? In: Revista Nomos. v. 33, n.2, 2013, p.26. 
sociedade pode utilizar para influenciar nas decisões tomadas são objeto de outro grande debate. De qualquer modo, aqui não se voltará a toda a discussão acerca do conflito, de sua realidade ou aparência, ou ainda dos argumentos favoráveis e desfavoráveis à ingerência judicial. Parte-se, desde logo, da conhecida posição defendida, entre outros, por Ronald Dworkin ${ }^{5}$, que acarreta a defesa da atuação do Poder Judiciário quando direitos fundamentais estiverem envolvidos. Decorre de seus ensinamentos a ideia de que o judiciário tem o dever de intervir sempre que uma decisão política afete um direito individual.

Afigura-se interessante enfatizar que a inserção do Poder Judiciário no ambiente dos direitos fundamentais é mandamento constitucional e, de igual modo, imposição da democracia, uma vez que há órbitas concêntricas nas quais gravitam os poderes constituídos, cada um com sua teia funcional, mas todos em torno do mesmo núcleo atrativo: a democracia constitucional.

O problema enfrentado no texto é a possibilidade de justificação de uma decisão judicial que interfere em uma decisão política a partir dos ensinamentos de Robert Alexy. A metodologia utilizada implicou a análise da legislação do setor portuário, para configurá-la como integrante do que se denomina de política pública, da análise da doutrina que entende ser possível a manifestação judicial em tais casos; e da análise dos autos escolhidos como exemplo de que a generalização pretendida por muitos não é possível. Assim, aplica-se a ponderação para demonstrar que no caso concreto escolhido a interferência do Judiciário decorre de exigência constitucional.

Um dos objetivos do texto é demonstrar que não engrandece a teoria constitucional a generalização da situação. De fato, na leva dos que advogam contra a possibilidade de "ingerência" do Judiciário, encontram-se diferentes aspectos da "ingerência". É possível que todos os que advogam contrariamente se vejam em apuros ao tentar justificar suas posições se lhes forem apresentados casos concretos diferentes, como a jurisprudência citada ao final. E se poderia partir dos mesmos fundamentos e critérios ao avaliar atuações judiciais que compelem o Executivo a pagar um remédio que pode salvar a vida de um 5 DWORKIN, Ronald. Uma Questão de princípio, Tradução Luiz Carlos Borges, São Paulo: Martins Fontes, 2000. 
indivíduo e cujo ingresso na lista do RENAME tem sido solicitado pelos médicos; a decisão que determina que sejam previstos no orçamento do ano seguinte os recursos para construção de uma creche; ou a decisão que determina que um direito fundamental como o de expressão seja respeitado!

Outro objetivo é observar se o modo com que o Judiciário interfere pode ter consequências diversas. Assim, observando especificamente uma decisão, o texto procura nela encontrar justificativas para acenar a favor ou contra a manifestação do Judiciário em questões políticas, se é que se está tratando de questão política ainda ou, ao judicializá-la, migrou para outro padrão de questão. Trata-se de decisão proferida em autos que discutem a forma de efetiva participação popular em processos licitatórios de portos no Brasil, à luz da legislação, bem como de uma decisão administrativa, portanto a partir de ato produzido no seio do órgão composto por representantes do povo, o Congresso Nacional e ato concebido pelo Poder Executivo, os quais, em princípio, deveriam estar sintonizados, mas em algum momento sugerem bifurcação.

\section{O SETOR PORTUÁRIO NO BRASIL COMO OBJETO DE POLÍTICA} PÚBLICA

A elaboração de uma política pública depende da iniciativa do Estado, seja provocado pela população, por um fato, por uma pesquisa, pelo anseio de reeleição ou por interesses políticos genericamente falando. De alguma forma, o tema entra na agenda do Estado indicando que reflete alguma importância.

O setor portuário tem importância evidente no desenvolvimento de qualquer país, no mínimo por ser um modal que permite o escoamento de produção, assim como representa porta de entrada de bens. Para um país com as características geográficas do Brasil, com mais de sete mil quilômetros de fronteira marítima, o cuidado com a questão deve ser ainda maior. Há uma questão logística a ser considerada, refletida nas possibilidades de transporte e de desenvolvimento. Há ainda uma de estratégia de segurança.

Com tudo isso em mente, o Constituinte de 1988 manteve notexto constitucional 
a competência da União para explorar, diretamente ou mediante autorização, concessão ou permissão, os portos e os serviços de transportes entre os portos brasileiros ${ }^{6}$. Para tanto, dá à União Federal a competência privativa para legislar sobre o regime de portos no Brasil. A União exerce esse seu papel constitucional por meio da Agência Nacional de Transportes Aquaviários (ANTAQ), criada em 2011 pela Lei n. 10.233 como autarquia vinculada ao Ministério dos Transportes e à Secretaria de Portos da Presidência da República (criada em 2007), quando foi deslocado o tema da infraestrutura marítima do Ministério dos Transportes para sua responsabilidade. É ela responsável pela implementação das políticas formuladas pelo Ministério dos Transportes e pelo Conselho Nacional de Integração de Políticas de Transporte (CONIT). Com essa estrutura institucional, em 2012, o Governo editou a Medida Provisória n. 595, posteriormente convertida na Lei 12.815/2013, que passa a ser o marco regulatório para o setor portuário, sob a denominação de Programa de Investimento em Logística: Portos. O artigo $3^{\circ}$ da mencionada lei dá a exata dimensão da decisão política tomada no sentido dos rumos da exploração de portos no Brasil e assim dita:

Art. $3^{\circ} \mathrm{A}$ exploração dos portos organizados e instalações portuárias, com o objetivo de aumentar a competitividade e o desenvolvimento do País, deve seguir as seguintes diretrizes:

I - expansão, modernização e otimização da infraestrutura e da superestrutura que integram os portos organizados e instalações portuárias;

II - garantia da modicidade e da publicidade das tarifas e preços praticados no setor, da qualidade da atividade prestada e da efetividade dos direitos dos usuários;

III - estímulo à modernização e ao aprimoramento da gestão dos portos organizados e instalações portuárias, à valorização e à qualificação da mão de obra portuária e à eficiência das atividades prestadas;

IV - promoção da segurança da navegação na entrada e na saída das embarcações dos portos; e

6 Art. 21, XII, 'd' e 'f' da Constituição Federal. 
$V$ - estímulo à concorrência, incentivando a participação do setor privado e assegurando o amplo acesso aos portos organizados, instalações e atividades portuárias.

A implementação destes objetivos ocorrerá pelas ações das pessoas jurídicas criadas para regulamentar e executar ações neste setor. A Lei 10.233/2001, entre outras, cria a Agência Nacional de Transportes Aquaviários e dispõe, em seu artigo 68, que as iniciativas de projetos de lei, alterações de normas administrativas e decisões da Diretoria para resolução de pendências que afetem os direitos de agentes econômicos ou de usuários de serviços de transporte serão precedidas de audiência pública.

Assim, já na criação da Agência restou estabelecido pelo legislador que as decisões que afetem agentes econômicos ou usuários do serviço deverão ser tomadas com base no que a população interessada tenha a dizer.

Há, portanto, clara opção do legislador em adotar uma política pública para o setor de transporte marítimo que leve em consideração as manifestações de agentes econômicos envolvidos e de usuários. Estas manifestações ocorrem por escrito previamente à realização da audiência pública ou, oralmente, na própria audiência. Esclareça-se que a própria legislação está mencionando a necessidade de realização de audiência pública.

As audiências públicas surgem no cenário nacional na Constituição de 1988 para, entre outros ${ }^{7}$, permitir que as comissões do poder legislativo possam ouvir a sociedade civil organizada ${ }^{8}$. As audiências públicas são um instrumento de exercício democrático ao permitir a participação da população nas decisões tomadas por um órgão.

The Right to a fair hearing é como o direito americano trata a audiência pública, prática que o direito anglo-saxão forjou, precisamente, para legitimar as ações e as opções administrativas para dar transparência à Administração e 7 Em diferentes artigos a Constituição de 1988 prevê a participação popular como o 31 , § $3^{\circ}$ ou o 74 , § $2^{\circ}$ A partir daí, diferentes legislações passaram a prever a possibilidade de oitiva da população.

8 Art. 58. O Congresso Nacional e suas Casas terão comissões permanentes e temporárias, constituídas na forma e com as atribuições previstas no respectivo regimento ou no ato de que resultar sua criação...

$\S 2^{\circ}$ - Às comissões, em razão da matéria de sua competência, cabe:...

II - realizar audiências públicas com entidades da sociedade civil; ... 
proporcionar eficiência. Em consequência, longe de traduzir mera formalidade, deve respeitar aos princípios constitucionais e, assim, alcançar a legitimação almejada. Não se trata apenas do direito fundamental dos cidadãos participarem das opções e das ações administrativas do Estado, mas a imposição legal em situações específicas trazidas, e.g., na hipótese de obras de vulto, prevista no artigo 39 da Lei 8.666/93.

Isso ocorre porque a EC 19/98 eleva a eficiência da Administração Pública ao patamar de direito fundamental de todos e, assim, obriga a otimização das ações e das opções administrativas, inclusive, assegurando aos administrados a legítima participação no procedimento que contemple a possibilidade de obter decisão ótima, sem escolhas arbitrárias pautadas em simulacro participativo, mas prestigiando a efetiva participação popular. Se no âmbito federal e desde que haja omissão em lei específica, a Lei 9.784, de 29.01.1999, que regula o processo administrativo no âmbito da Administração Pública Federal, deverá ser aplicada, uma vez que prevê, expressamente, a audiência pública.

A Agência Nacional de Transportes Aquaviários editou, em 2012, a Resolução n. $2448^{9}$, aprovando o regulamento das audiências públicas realizadas pela mesma. $\mathrm{O}$ artigo $2^{\circ}$ do Regulamento estabelece que são objetivos da realização das audiências públicas:

I - colher sugestões e contribuições para subsidiar o processo decisório da ANTAQ e a edição de atos normativos;

II - propiciar à sociedade civil e aos agentes regulados a possibilidade de encaminhar sugestões e contribuições;

III-identificar, da forma mais ampla possível, todos os aspectos relevantes à matéria submetida ao processo de participação democrática;

IV- dar maior legitimidade aos atos normativos e decisórios emitidos pela ANTAQ; e

9 Disponível em: www.antaq.gov.br/Portal/pdfSistema/Publicacao/0000005665.pdf. Acesso em: 03.02.14. 
V - dar publicidade à ação da ANTAQ.

Resulta do dispositivo que as audiências públicas realizadas por esta autarquia devem permitir a participação efetiva da sociedade, uma vez que ali poderá receber sugestões e colaborações populares essenciais à eficiência da Administração, conforme o inciso I que traça como objetivo da audiência pública "colher sugestões e contribuições para subsidiar o processo decisório da ANTAQ". Desta expressão extrai-se que a sociedade tem a chance de expressar sua participação por meio de petição enviada para estimular, instigar, cooperar, contribuir e auxiliar ${ }^{10}$ na busca da legitimação das ações e das opções da Administração.

Apesar de a Resolução estabelecer que as sugestões e as contribuições colhidas durante as audiências públicas são de caráter consultivo e não vinculante, isso não configura qualquer demérito ao instrumento. De fato, o inciso I, anteriormente citado, afirma que as contribuições servem 'para subsidiar o processo decisório' e, assim, exige que os argumentos trazidos sejam levados em consideração. Em outras palavras, a Administração está não só obrigada a ouvir o público, mas também a fazer a rejeição fundamentada de seus fundamentos, eis que esta é a única maneira de fazer com que as sugestões possam 'subsidiar o processo decisório'.

A Resolução estabelece os procedimentos para a realização da audiência pública, deixando ao Presidente da mesma certo grau de discricionariedade acerca do modo como as contribuições serão colhidas. É o que se conclui do artigo $5^{\circ}$, que dita:

"A manifestação dos interessados, na audiência pública presencial, dependerá de inscrição, sendo facultado o oferecimento de documentos ou arrazoados, devendo a apresentação oral de cada interessado, se for o caso, respeitar a duração estabelecida pelo Presidente da audiência pública".

Por meio do Aviso de consulta e audiência pública n. 7/2013, a Agência Nacional de Transportes Aquaviários deu publicidade à realização de audiência pública presencial para discussão dos processos de licitação para a exploração de áreas e infraestruturas portuárias por meio de arrendamentos junto aos portos

10 Conforme definição do Novo Dicionário Aurélio, pps. 1891 e 494. 
organizados de São Sebastião (Companhia Docas de São Sebastião), Salvador e Aratu (Companhia das Docas do Estado da Bahia - CODEBA) e Paranaguá (Administração dos Portos de Paranaguá e Antonina - APPA). O modo de realização da coleta das sugestões e das colaborações de agentes econômicos e usuários foi disciplinado pela ANTAQ por meio de documento disponibilizado em seu sítio eletrônico, denominado "Regras de Funcionamento da Audiência Pública no 7/2013". As regras estabeleceram que as contribuições deveriam ser ofertadas, tão somente, previamente e via sítio eletrônico. Durante a audiência, a mesa que dirige os trabalhos faria esclarecimentos sobre o objeto da audiência, reservando-se o direito de não discutir as contribuições que tivessem sido feitas, deixando para manifestar-se sobre elas no próprio sítio eletrônico. Veja-se o que consta da regulamentação:

... 2. A Mesa fará os esclarecimentos que se fizerem necessários sobre o objeto da presente Audiência, mas se reservará o direito de não discutir de imediato as contribuições ofertadas, o que será feito por escrito no sítio eletrônico da ANTAQ, após análise técnica e jurídica da Agência;...

Perceba-se, no entanto, a primeira incongruência. Se as colaborações deveriam ser feitas pelo sítio, antes da audiência, por que não discuti-las na audiência? Afinal, se a intenção é que pudessem ser objeto de maior reflexão pela agência, inclusive por seu setor jurídico, o tempo necessário para tanto estaria reservado pela própria obrigatoriedade de enviar as manifestações via sítio eletrônico. Mas se o objetivo da política pública adotada era receber as contribuições para enriquecer o processo de decisão, por que não aproveitar o momento da audiência para que os interessados pudessem conhecer os motivos de recusa de atendimento de suas reivindicações e/ou sugestões? Em outras palavras, é do próprio texto da lei que se retira o objetivo da audiência pública de "identificar, da forma mais ampla possível, todos os aspectos relevantes à matéria submetida ao processo de participação democrática", se esses aspectos relevantes podem ser produto da contribuição dos interessados, a resposta aos mesmos, nem que seja para justificar o não atendimento de suas reivindicações, deveria vir em momento em que o diálogo ainda é possível. Estabelecer momento posterior para trazer as 
justificativas de negativa é fazer pender a balança para a própria Administração, que não estará sujeita aos argumentos dos interessados que pudessem levar a um resultado diferente.

Há situações nas quais o volume de material técnico produzido na participação popular não permite que a discussão ocorra naquela primeira audiência, dada a complexidade da análise demandada, razão pela qual outra deverá ser agendada para, aí sim, possibilitar o salutar e contributivo debate entre as motivações da Administração e as ponderações de quem produziu a documentação, avivando a legitimidade e o amplo e participativo viés popular, cooperando, assim, para que as ações e as opções do Poder Público sejam arrimados na maior e mais eficaz discussão possível entre os atores sociais.

Mas as dificuldades para real implantação do quanto fixado na legislação que previu a realização de audiências públicas não para aí. A regulamentação desta audiência ainda estabeleceu tempo de dois minutos para que cada inscrito se manifestasse, podendo a mesa interromper a fala se decorrido o tempo. Ora, o objeto das licitações é de grande complexidade e importância ${ }^{11}$, envolve tantos detalhes que o tempo de dois minutos é exíguo para que alguém possa fazer sua contribuição, quiçá de modo fundamentado. Aqueles acostumados à matéria e que confortavelmente podem apontar melhorias possíveis no sistema atestam a exiguidade do tempo franqueado. Para além disso, qualquer cidadão que pretendesse veicular sua contribuição/ reivindicação, por mais singela que fosse, mal poderia fundamentar seu pedido em tempo tão curto. Mas isso é o quanto estabelecido para a possibilidade de manifestação no ato da audiência, ou seja, quando o interessado está pessoalmente na audiência aguardando sua vez de manifestação.

Em relação à manifestação prévia, por escrito, no sítio eletrônico, também houve a previsão de restrições. Veja-se que o sítio somente permitia a inserção de mil caracteres, tolhendo, novamente, o direito de manifestação. Se o comando legislativo determina a oitiva dos interessados para que a administração possa tomar uma melhor decisão, o objetivo não é alcançado com a regulamentação editada pela Agência.

11 O Governo Federal espera investimentos da ordem de $\mathrm{R} \$ 54$ bilhões em arrendamentos de terminais portuários. As informações completas estão em www.planejamento.gov.br. 
É evidente que o modo de exercício desta possibilidade de participação, tão essencial na conformação de políticas públicas, tolhe não somente o direito de participação, conquistado a duras penas e finalmente reconhecido na legislação infraconstitucional que criou a Agência Nacional de Transporte Aquaviário, mas também subverte a lógica de implantação da própria política pública. A regulamentação dada pela Agência especificamente no que diz respeito à audiência pública, já prevista em legislação federal que criou a agência, está muito aquém das possibilidades de realização do comando constitucional.

Diante disto, foi proposta ação popular ${ }^{12}$ para suspender os efeitos da regulamentação da audiência pública que se avizinhava. Levou-se, então, ao Poder Judiciário, uma decisão política do Executivo circunscrita à obrigatoriedade de realização da audiência pública para formatação de uma política pública e ao seu modo de concretização. A reclamação era fundamentada, em termos gerais, em dispositivos constitucionais que franqueiam o direito de petição e a liberdade de expressão. A ação foi proposta perante a Justiça Federal, em Salvador - Bahia, e o juiz levou em consideração a complexidade do processo de implementação da política pública e a real possibilidade de participação nos moldes regulamentados, em suas palavras:

De outro lado, é verdade que a restrição para que a consulta não ultrapasse mil caracteres, imposta pela ré, limita a participação dos interessados que devem ter direito e acesso a um amplo debate para dirimir eventuais dúvidas, suscitar questionamentos, dar sugestões. Tal limitação, por consequência, termina por cercear o direito de petição $\left(C F\right.$, art. $\left.5^{\circ}, X X X I V, a\right)$ e a liberdade de expressão (CF, art. $\left.5^{\circ}, \mathrm{V}\right)$ dos interessados.

Do mesmo modo, a cláusula 6 das Regras de Funcionamento da Audiência Pública n. 7/2013, que diz que: "Cada inscrito terá 2 (dois) minutos para manifestarse oralmente, podendo a mesa interromper a fala, caso o tempo definido seja ultrapassado", também cerceia o direito de petição e a liberdade de expressão dos interessados, uma vez que o tempo dado é muito exíguo para dirimir eventuais dúvidas, suscitar questionamentos ou dar sugestões, notadamente considerando

12 Autos n. 3746-93.2013.4.01.3300 da Seção Judiciária da Bahia. 
a complexidade da matéria que será tratada na audiência pública em questão.

Com base nisto, a magistrada responsável pelos autos entendeu por bem conceder a liminar para evitar maiores danos aos interessados em participar, verbis:

...para determinar as contribuições de que cuida a cláusula I das Regras de Funcionamento da Audiência Pública n. 7/2013 possam ser feitas sem a restrição de caracteres imposta. Por consequência, determino que, caso não seja possível a realização da contribuição por meio do sitio eletrônico da ANTAQ, sem a limitação dos mil caracteres imposta, que possibilite a ré a oferta de eventuais contribuições dos interessados por meio de adendos, escritos ou por algum outro meio eletrônico.

Outrossim, determino que a manifestação oral de que cuida a cláusula 6 das Regras de Funcionamento da Audiência Pública n. 7/2013 possam ser feitas no tempo de 10 (dez) minutos e não de 2 (minutos) como ali previsto, tendo em vista a importância e complexidade do tema.

Neste caso, há uma intervenção do Poder Judiciário não só pertinente, mas acertada pelos parâmetros constitucionalmente estabelecidos e, ainda, previstos na legislação infraconstitucional. O desvio do objetivo está presente tão somente no ato da própria Agência reguladora do setor que, ao utilizar-se de sua prerrogativa de regulamentar o modus operandi de uma audiência pública, o fez para torná-la um mero requisito formal a ser cumprido, retirando-lhe toda a importância que poderia apresentar.

Mas a atuação do Poder Judiciário em relação a este assunto não se limitou a esta decisão. Como a regulamentação da audiência pública se fez para a previsão de licitação também para o Porto de Paranaguá, no Paraná, os trabalhos da mesa obedeceriam às mesmas regras. Como a audiência neste Estado ocorreu em momento posterior ao da concessão da liminar mencionada, e como a agência já havia sido intimada da mesma, a postura da agência foi diferenciada.

Desse modo, no início dos trabalhos desta audiência, a mesa informou aos presentes acerca da decisão judicial anteriormente transcrita e, assim, franqueou tempo maior para as manifestações presenciais e garantiu o direito de protocolo 
de manifestações escritas, sem o limite de caracteres antes impostos. Assim, concedeu aos interessados cinco dias para o envio de manifestações. Com base nisso, o Sindicato dos Operadores Portuários do Paraná (SINDOP) protocolou manifestação escrita, fruto de meses de estudos e debates, acompanhada de estudos técnicos, gráficos, mapas, plantas, fotografias e planilhas. A resposta da ANTAQ veio no mesmo dia, no sentido de que os documentos protocolados poderiam não ser analisados, eis que o protocolo deveria ser feito somente via sítio eletrônico. Como o sítio eletrônico, apesar de possibilitar, então, a inclusão de contribuições com mais de mil caracteres, não permitia a anexação de qualquer documento, todo o trabalho do Sindicato seria desconsiderado.

Assim, nova medida judicial foi movida ${ }^{13}$, levando-se ao Poder Judiciário a notícia da ANTAQ de que a colaboração protocolada pelo Sindicato poderia não ser analisada. Novamente, com fundamento no direito de petição e de liberdade de expressão, acrescido ao direito de obter resposta da Administração Pública, o Poder Judiciário, pelo magistrado de primeiro grau, decidiu a favor do Sindicato:

...para determinar que a autoridade impetrada aceite as contribuições apresentadas pelo impetrante, em meio físico, por meio dos Ofícios no 73, 74, 75, 76 e 77, protocolados em 24/10/2013, analisando e apresentando resposta em tempo hábil, ou seja, antes de enviar ao Tribunal de Contas da União as minutas de Editais e Contratos de Concessão alusivos aos leilões de instalações portuárias no Porto de Paranaguá.

E é aqui que a atuação do Poder Judiciário merece atenção. Veja-se a extensão da decisão: a ANTAQ estava na iminência de dar prosseguimento a um procedimento licitatório, parte evidente da política pública adotada para o setor. A política pública foi desenhada por legislação que exigiu a oitiva de partes interessadas e que estas pudessem dar contribuições. Correto concluir que o poder legislativo, composto pelos escolhidos pela população, desenhou um modo específico de elaboração de políticas públicas e de tomada de decisões neste setor específico.

13 Autos n.11042-75.2014.4.01.3400 da 4ª Vara Federal da Seção Judiciária do Distrito Federal. 
Apesar de a Resolução, em seu art.11, II, expressamente prever a necessidade de apresentação de resposta pela Administração, não foi na aplicação deste artigo que o Poder Judiciário encontrou a solução para a questão. Os objetivos da oitiva estão previstos no momento em que a legislação estabeleceu os objetivos da realização de audiências públicas. O Judiciário, interpretando a norma, esclareceu que a oitiva não pode ser uma fase simplesmente formal, de cumprimento objetivo do quanto se depreende da análise semântica da lei. Muito mais do que isso, o Judiciário buscou nos objetivos estabelecidos pela lei a resposta para o significado das regras postas e concluiu que as contribuições merecem justa consideração da Administração Pública, por isso, não se limitou a determinar que as considerações fossem recebidas. Foi além, e determinou que, se forem rechaçadas, devem o ser de modo a que os administrados saibam os fundamentos para tanto.

Exatamente o que afirmou o magistrado quando determinou que a administração apresentasse resposta às considerações em tempo hábil, ou seja, antes do envio do processo à próxima fase. Diante do exíguo prazo de tempo entre o termo final para a juntada de contribuições e a data prevista para que o processo fosse encaminhado à sua ulterior fase, parece correto concluir que, sem essa decisão, fatalmente as considerações não teriam reflexo algum no processo, e mais, restariam frustrados os fundamentos constitucionais que respaldam a participação popular e, ao fim, a própria inutilidade da audiência pública, abrindose uma porta enorme aos anseios criativos e arbitrários do administrador.

\section{DA INTERFERÊNCIA DO PODER JUDICIÁRIO EM POLÍTICAS} PÚBLICAS

Esse não é o espaço para se discorrer acerca de todos os argumentos a favor e contra a interferência do Poder Judiciário nas questões políticas em geral e nas políticas públicas em particular ${ }^{14}$. Todavia, como o objetivo do trabalho é argumentar sobre o acerto ou não da decisão escolhida, alguma menção ao assunto precisará ser feita.

14 MENDES, Conrado H. Is it All About the Last Word? Deliberative Separation of Powers 1 (July 1, 2009). Legisprudence, Vol. 3, No. 1, pp. 69-110, 2009. Available at SSRN: http://ssrn.com/abstract=1911822, s/p. 
Ran Hirschl, em seu festejado Towards juristocracy: the origens and consequences of the new constitucionalism, publicado em 2004, pela Harvard University Press, em Cambridge, sugere um habitat megapolítico, ou de política pura, na qual a inserção judicial brasileira se hospedara e aponta outros sítios de hospedagem judicial da política, tais como a eleição americana, Bush X Al Gore e a discussão sobre o papel da Alemanha na Zona do Euro.

Lênio Streck ${ }^{15}$ sustenta que a judicialização da política é aspecto secundário em relação ao quantum de judicialização que deve ser ministrado. Não parece ser, ou dever ser, assim, porque a questão radica, precisamente, na conquista democrática representada pelo Poder Judiciário no papel de guardião final dos direitos fundamentais ameaçados em qualquer seara, inclusive na política.

Exsurge interessante necessidade de avaliar a democracia e a constituição sob duas perspectivas: democracia como valor inspirador da constituição integral e como princípio inserto na constituição, ou seja, princípio jurídico. Sem pretender descer a minúcias sobre tema tão caro e complexo, não se pode deixar de encarecer a importância de separar democracia contemporânea (na qual a maioria não expressa a força anteriormente presente naquele conceito, a ponto de concebêla como governo da maioria), constituição e princípios constitucionais.

Pois bem, um conjunto de regras institucionalizadas que estabeleçam a quem compete a tomada de decisões é, no ambiente contemporâneo, o catalizador da democracia, evidentemente, sem olvidar a importância da maioria, jamais sua preponderância. A clareza do jogo político e do exercício do poder, ou seja, quem deve tomar decisões coletivas e sob quais procedimentos, traduzem o conceito atual de democracia, como defendia Norberto Bobbio ${ }^{16}$, e mais, inspirado em valores éticos, políticos e jurídicos, na convivência pacífica e de realização dos direitos humanos a todos os homens em qualquer lugar, enfim o respeito à dignidade humana.

15 STRECK, Lenio Luiz A influência do sistema presidencialista no ativismo judicial do Supremo Tribunal Federal brasileiro - quem deve efetivar os direitos fundamentais em uma democracia. In: ALEXY, Robert et.al. NÍVEIS DE EFETIVAÇÃO DOS DIREITOS FUNDAMENTAIS, CIVIS E SOCIAIS: UM DIÁLOGO BRASIL E ALEMANHA. Joaçaba: Ed. Unoesc, 2013. cap. II, p.173-196. 
Aqui não se pode deixar de apontar a recentíssima passagem do filósofo do direito de maior relevo na Alemanha, Robert Alexy, em Chapecó, Santa Catarina, quando se manifestou sobre a proteção dos direitos fundamentais sociais na sociedade globalizada e sobre o seu trabalho mais recente e até então inédito, não positivismo inclusivo, no qual enfatiza a necessidade cada vez maior de desdobrar a norma jurídica em princípios e regras, bem como a necessidade de utilizar o método do balanceamento de princípios conflitantes à luz do caso concreto ${ }^{17}$.

A técnica da proporcionalidade é criticada por alguns autores em razão da possibilidade de subjetivismos do intérprete (juiz), mas não se pode contestar que se revela como a metodologia mais bem acabada da interpretação sistemática. Ademais, no aparente conflito entre uma regra e um princípio, poderia prevalecer a regra, numa perspectiva inicial, porque, em primeiro lugar, a distinção que faz entre um e outro não está na fundamentalidade, mas sim em sua estrutura normativa e, em segundo lugar, uma das ideias subjacentes aos princípios é a pretensão de correção. Com efeito, na ocorrência de conflito entre um princípio e uma regra ${ }^{18}$, a solução deve vir da ponderação entre este princípio e o princípio que fundamenta a regra colidente.

Pela lógica, se os princípios (com pretensão de correção) informam as regras (também com pretensão de correção), estas devem ter maior poder de clareza e correção, portanto seriam prevalentes. Todavia, pode haver conflito entre princípio e regra, no qual aquele deverá prevalecer, se o princípio que colide com aquele que informa a pretensão de correção da regra é mais forte e, assim, deverá prevalecer o princípio à regra. É só uma questão de estrutura de norma.

Nesse diapasão, convém frisar excelente conferência do Prof. Matthias Klatt ${ }^{19}$,

17 Proporcionalidade, Dignidade Humana e Direitos Sociais na Teoria dos Direitos Fundamentais. Conferência proferida pelo Prof. Dr. Robert Alexy UNOESC - Chapecó/SC de 26 a 28.03.2014. In: Caderno de Formação $n^{\circ} 1$, Ano 2014, Escola Judicial TRT $12^{a}$ Região.

18 Convém a leitura de um texto esclarecedor acerca da distinção entre regras e princípios, da lavra de Virgílio Afonso da Silva, no qual esboça com maestria os dogmas da doutrina constitucionalista tradicional e a ênfase dada ao aspecto da fundamentalidade dos princípios como se fosse um pilar restrito dessa espécie normativa e não fosse, igualmente, característica da outra espécie, ou seja, das regras, a saber: Princípios e regras: mitos e equívocos acerca de uma distinção. In: Revista Latino-Americana de Estudos Constitucionais no. 1, 2003, pp. 607-630.

19 Professor da Faculdade de Direito da Universidade de Hamburgo (UNIVERSITÄT HAMBURG) e autor do livro The constitutional Structure of Proportionality, publicado pela Oxford University Press em 2012. O Prof. Klatt fez seu doutoramento em Direito sob a orientação do Prof. Dr. Mult. H. C. Robert Alexy. 
proferida no mesmo evento em Chapecó-SC, "Objeções ao uso do teste da proporcionalidade e os caminhos do Estado Constitucional de Direito", na qual aborda a instigante questão acerca do teste da proporcionalidade e as suas repercussões no que diz respeito às competências de cada uma das funções do poder (executivo, legislativo e judiciário).

Afirma Klatt ${ }^{20}$ que:

...o Judiciário, ao aplicar o teste da proporcionalidade, balanceando princípios aparentemente conflitantes no caso concreto, pode efetuar uma escolha (por exemplo, aplicar o princípio da dignidade da pessoa humana em detrimento do princípio da separação de funções de poder e do princípio da reserva do possível, outorgando um medicamento a uma determinada pessoa que dele necessita, mas de custo muito caro e fora das listas de medicamentos de distribuição pública e gratuita) e, com isso, afetar a competência que seria do executivo ou do legislativo, atingindo o princípio do estado democrático de direito.

Klatt ${ }^{21}$ sustenta que as repercussões dessa natureza são muitíssimo complicadas de evitar, mormente diante de hard cases, ou casos difíceis, e o teste da proporcionalidade (adequação, necessidadee proporcionalidadeemsentidoestrito), a despeito das críticas que pode sofrer (entre elas a da invasão de competências), ainda é a metodologia mais adequada para harmonizar o sistema jurídico à luz do caso concreto, uma vez que permite a construção racional e justificada da escolha pelo princípio (ou solução jurídica) que irá preponderar no caso posto em exame.

Com efeito, encontra-se no plano de análise mais profundo, ou seja, dos fundamentos do direito, a partir do qual as demais teorias jurídicas traçam seus contornos. Neste ambiente, é possível esquadrinhar os rudimentos do positivismo e do não positivismo, pautados na relação entre direito e moral.

Daí resulta a imperativa constatação da conexão conceitual necessária entre o direito e a moral, conexão não admitida pelos positivistas em suas espécies, uma vez que, para o positivismo exclusivo, a moral está excluída da noção de direito; para o positivismo inclusivo, a moral, apesar de não estar necessariamente presente na noção de direito, pode se fazer presente eventualmente.

20 The constitutional Structure of Proportionality, p.42.

21 The constitutional Structure of Proportionality, pp.76 a 80. 
Por isso, Alexy defende que as normas jurídicas, ainda que apresentem algum defeito moral, são válidas e, apoiado na Fórmula de Radbruch ${ }^{22}$, conclui que apenas aquelas normas jurídicas que gerem situações de extrema injustiça terão sua validade comprometida. Por isso, o não positivismo inclusivo é a corrente que melhor representa uma concepção dual do direito, abrangendo tanto uma dimensão fática quanto uma dimensão ideal ${ }^{23}$.

Desse modo, o sistema jurídico autoriza, sem que haja qualquer mácula à democracia e à tripartição de funções, que os direitos fundamentais sejam protegidos pelo Poder Judiciário quando a ele demandados. Sempre que os direitos fundamentais estiverem vertidos em forma de princípios, a melhor solução para chegar ao prevalecente passa pela utilização do método do balanceamento com a análise racional das interferências em um princípio $\mathrm{P} 1$ e o peso do princípio $\mathrm{P} 2$, em colisão, por meio da fórmula da proporcionalidade e do modelo triádico que classifica as interferências em leve, média e séria.

A situação concreta aqui discutida versa sobre o direito fundamental de participação social no procedimento democrático e constitucional de audiência pública. Este direito é colocado sob ameaça pela atuação do poder público, na função executiva, que é limitada pelo ordenamento jurídico e deve respeitar o princípio democrático - porque positivado no Texto Constitucional -, bem como a democracia como valor que nutre a concepção e forja a própria Constituição. Nada mais legítimo, portanto, do que a inserção do poder público na função jurisdicional para restaurar o direito fundamental sob espancamento.

Evidentemente, não se está aí tratando de "ingerência" de um poder na função de outro, não há quebra democrática, mas legítima atuação funcional do Poder Judiciário que, sopesando os valores em contraste, ou aparentemente em colisão, faz prevalecer o direito fundamental de expressão popular em detrimento, se

22 Arbitrariedad Legal y Derecho Supralegal. Buenos Aires: Abeledo - Perrot, 1962. Filosofia do Direito. Coimbra: Coleção STVDIVM, Armênio Amado Editor, 1974.

23 Para Alexy, a dimensão ideal do direito é aquela que não afasta a norma com defeito moral do mundo do direito, a não ser que haja uma extrema injustiça e, assim, teria validade comprometida. No "não positivismo superinclusivo", uma norma que apresente um defeito moral é uma norma defeituosa, mas permanece válida em todos os casos, o que não é ideal, porque se acarretar a "extrema injustiça" (Radbruch) não será válida. Trata-se de momento posterior à teoria dos princípios, no qual a principal obra é Conceito e validade do direito, 2002, quando Alexy desenvolve uma teoria que associa direito e moral. 
assim alguns pretenderem entender, do direito fundamental tripartite.

E, note-se, não há colisão entre os princípios, ela é apenas aparente, uma vez que a Constituição estará protegida com a prevalência do direito fundamental P1, relativamente ao direito fundamental $\mathrm{P} 2$. Se a interferência gravíssima naquele ocorrer diante das condições fáticas e jurídicas concretamente analisadas, enquanto neste, dadas as tais condições concretas, a interferência é leve - frisese, para aqueles que visualizam alguma interferência no segundo princípio -, ainda não há razão para afastar a atuação judicial.

Resta demonstrado, portanto, que os argumentos contrários ou favoráveis à atuação judicial não podem ser avaliados em abstrato. De fato, a julgar pela aplicação das lições de Alexy, necessário é que o foco esteja em um caso concreto em que seja possível aplicar os princípios e as regras que podem incidir na situação. Essa aplicação permitirá avaliar se a ingerência do Judiciário é efetivamente indevida, ou se está assegurando princípios constitucionais que, utilizada a regra da ponderação, demonstram ter maior peso diante daquele caso concreto. A tarefa é sempre definir o peso dos princípios democráticos (e o de participação popular, no caso aqui avaliado) e da tripartição dos poderes frente à situação fática, porque ao se pretender avaliar o entrechoque de princípios, o sopesamento dos direitos fundamentais em jogo de colisão só pode ser feito in concreto.

\section{CONSIDERAÇÕES FINAIS}

Veja-se, então, que apesar de todas as teorias que são pensadas em torno da possiblidade ou não do Poder Judiciário se imiscuírem em atividades políticas, talvez se tente abarcar todas as possibilidades de manifestação do Judiciário nestes casos, de modo um tanto maniqueísta.

O que parece saltar aos olhos com a decisão aqui mencionada é que nem aqueles que defendem os argumentos contrários à atuação judicial poderiam se opor à interferência representada por esta decisão. Afinal, a decisão busca garantir justamente o espaço democrático que não se quer restringir quando a posição defendida rechaça a atuação judicial. 
Por outro lado não se vislumbra possibilidade de generalizar alguma regra que possa determinar objetivamente quando seria aceitável e quando não seria aceitável a ingerência do Judiciário em questões políticas. No presente caso, a decisão judicial está garantindo o direito de manifestação dos interessados e o direito de resposta que a Constituição prevê.

\section{REFERÊNCIAS}

ALEXY, Robert. Conceito e validade do direito, 2002. Proporcionalidade, Dignidade Humana e Direitos Sociais na Teoria dos Direitos Fundamentais. Conferência proferida por Robert Alexy na UNOESC - Chapecó/SC de 26 a 28.03.2014. In: Caderno de Formação n 1, Ano 2014, Escola Judicial TRT 12a Região.

BOBBIO, Norberto. O Futuro da Democracia. São Paulo: Saraiva, 2009.

BRASIL. Agência Nacional de Transportes Aquaviários. Disponível em: www.antaq.gov.br/ Portal/audiencia07_2013.asp, acesso em 15.04.14.

BRASIL. Agência Naciona de Transportes Aquaviários. Disponível em: www.antaq.gov.br/ Portal/pdfSistema/Publicacao/0000005665.pdf. Acesso em: 03.02.14.

DWORKIN, Ronald. Uma Questão de princípio. Tradução Luiz Carlos Borges. São Paulo: Martins Fontes, 2000.

FERREIRA, Aurélio Buarque de Holanda. Novo dicionário Aurélio da língua portuguesa. Coord. Marina Baird Ferreira, Margarida dos Anjos. 4. ed. Curitiba: Ed. Positivo, 2009.

KLATT, Mathias. MORITZ Meister. The constitutional Structure of Proportionality. London: Oxford University Press, 2012.

MENDES, Conrado Hübner. Is it All About the Last Word? Deliberative Separation of Powers 1 (July 1, 2009). Legisprudence, Vol. 3, No. 1, pp. 69-110, 2009. Available at SSRN: http://ssrn. com/abstract=1911822 or http://dx.doi.org/10.2139/ssrn.1911822.

RADBRUCH, Gustav. Arbitrariedad Legal y Derecho Supralegal. Buenos Aires: Abeledo Perrot, 1962.

RADBRUCH, Gustav. Filosofia do Direito. Coimbra: Coleção STVDIVM, Armênio Amado Editor, 1974. 
ROSSI, Amélia; PAMPLONA, Danielle Anne. Neoconstitucionalismo e ativismo judicial: democracia e constitucionalismo em oposição ou tensão produtiva? In: Revista Nomos. v. 33, n.2, 2013, pp.13/29.

SILVA, Virgílio Afonso da. Princípios e regras: mitos e equívocos acerca de uma distinção. In: Revista Latino-Americana de Estudos Constitucionais 1, 2003.

STRECK, Lenio Luiz. A influência do sistema presidencialista no ativismo judicial do Supremo Tribunal Federal brasileiro - quem deve efetivar os direitos fundamentais em uma democracia. In: ALEXY, Robert et al. Níveis de efetivação dos direitos fundamentais, civis e sociais: um diálogo Brasil e Alemanha. Joaçaba: Ed. Unoesc., 2013. cap .II, p.173-196.

Recebido em: abr/2015

Aprovado em: jun/2015 